Much to our regret, the first part of the Editors' Reply to Dr. Cheng's Letter [1] was omitted during production. The correct Editors' Reply should read as follows:

\title{
Editors' Reply
}

The Editors and Publishers would like to apologize to Dr. Zeymer and his co-authors [2] for having overlooked the fact that the acronym was highlighted in the final draft of their paper when it went into production.

We thank Prof. Cheng for his interest in Heart Drug and for pointing out the fact that acronyms have to be explained prior to being used.

References

1 Cheng TO: ESCAMI surely escapes me. Heart Drug 2001;1:182.

2 Zeymer U, Suryapranata H, Monassier JP, Opolski G, Davies J, Rasmanis

G, Tebbe U, Schröder R, Willberg M-L, Tiemann R, Machnig T, Neuhaus K-L for the ESCAMI Investigators: Evaluation of the Safety and $\underline{\text { Cardio- }}$ protective effects of eniporide, a specific sodium/hydrogen exchange inhibitor, given as adjunctive therapy to reperfusion in patients with Acute Myocardial Infarction (ESCAMI). Heart Drug 2001;1:71-76.

\section{KARGER}

(ㄱ) 2001 S. Karger AG, Basel

Fax +41613061234 